\title{
Transparent Ethylene-Bridged Polymethylsiloxane Aerogels and Xerogels with Improved Bending Flexibility.
}

\section{$\operatorname{AUTHOR}(S)$ :}

Shimizu, Taiyo; Kanamori, Kazuyoshi; Maeno, Ayaka; Kaji, Hironori; Nakanishi, Kazuki

\section{CITATION:}

Shimizu, Taiyo ...[et al]. Transparent Ethylene-Bridged Polymethylsiloxane Aerogels and Xerogels with Improved Bending Flexibility.. Langmuir : the ACS journal of surfaces and colloids 2016, 32(50): 13427-13434

\section{ISSUE DATE:}

2016-11-20

URL:

http://hdl.handle.net/2433/218200

\section{RIGHT:}

This document is the Accepted Manuscript version of a Published Work that appeared in final form in 'Langmuir', copyright (c) American Chemical Society after peer review and technical editing by the publisher. To access the final edited and published work see http://doi.org/10.1021/acs.langmuir.6b03249; The full-text file will be made open to the public on 20 November 2017 in accordance with publisher's 'Terms and Conditions for Self-Archiving'.; この論文は出版 社版でありません。引用の際には出版社版をご確認ご利用ください。; This is not the published version. Please cite only the published version. 


\section{Transparent Ethylene-bridged Polymethylsiloxane}

\section{Aerogels and Xerogels with Improved Bending}

\section{Flexibility}

Taiyo Shimizu', Kazuyoshi Kanamori ${ }^{*}{ }^{\prime}$, Ayaka Maeno ${ }^{\ddagger}$, Hironori Kaji ${ }^{\ddagger}$ and Kazuki Nakanishi ${ }^{\dagger}$

'Department of Chemistry, Graduate School of Science, Kyoto University, Kitashirakawa, Sakyo-ku, Kyoto 606-8502, Japan

Institute for Chemical Research, Kyoto University, Gokasho, Uji-city, Kyoto 611-0011, Japan

ABSTRACT: Transparent, monolithic aerogels with nano-sized colloidal skeletons have been obtained from a single precursor of 1,2-bis(methyldiethoxysilyl)ethane (BMDEE) by adopting a liquid surfactant and a two-step process involving strong-acid, followed by strong-base, sol-gel reactions. This precursor BMDEE forms the ethylene-bridged polymethylsiloxane (EBPMS, $\left.\mathrm{O}_{2 / 2}\left(\mathrm{CH}_{3}\right) \mathrm{Si}-\mathrm{CH}_{2} \mathrm{CH}_{2}-\mathrm{Si}\left(\mathrm{CH}_{3}\right) \mathrm{O}_{2 / 2}\right)$ network, in which each silicon has one methyl, two bridging oxygens and one bridging ethylene, exhibiting an analogous structure to that of the previously reported polymethylsilsesquioxane (PMSQ, $\mathrm{CH}_{3} \mathrm{SiO}_{3 / 2}$ ) aerogels having one methyl and three bridging oxygen atoms. Obtained aerogels consists of fine colloidal skeletons, and show high visible-light transparency and a flexible deformation behavior against compression without 
collapse. Similar to the PMSQ aerogels, a careful tuning of synthetic conditions can produce low density $\left(0.19 \mathrm{~g} \mathrm{~cm}^{-3}\right)$ and highly transparent $(76 \%$ at $550 \mathrm{~nm}$, corresponding to $10 \mathrm{~mm}$-thick samples) xerogels via ambient pressure drying by solvent evaporation, due to their high strength and resilience against compression. Moreover, EBPMS aerogels exhibit higher bending strength and bending strain at break against the three point bending mode, compared to PMSQ aerogels. This improved bendability is presumably derived from the introduced ethylene-bridging parts, suggesting the potential for realizing transparent and bendable aerogels in such polysiloxane materials with organic linking units.

\section{INTRODUCTION}

Silica aerogels, typically obtained by drying wet silica gels via a high-pressure drying technique utilizing a supercritical fluid, ${ }^{1}$ have a lot of unique properties such as high visible light transparency, high porosity and low thermal conductivity. ${ }^{2}$ Various applications taking advantage of these properties, such as high-performance insulating windows, ${ }^{3,4}$ Cherenkov radiators, ${ }^{5}$ antireflective layers for organic light emitting devices ${ }^{6}$ and carriers for drug delivery systems, ${ }^{7}$ have been explored so far. These unique properties are derived from the characteristic pore structure, composed of colloidal structural components in nanometer scales, that is, small pores (a few tens nanometers) and thin solid skeletons (ca. $10 \mathrm{~nm}$ ). ${ }^{2}$ However, such microstructure also imposes mechanical friability on aerogels, as well as the native brittleness of the silica network. In particular, even a small bending stress can cause macroscopic fractures in a gel body, and thus, cautious handling is required for processing silica aerogels. Although there are some reports on successful improvements in this friability by modifying the surface of pore 
skeletons with isocyanate, ${ }^{8}$ or forming a composite with cellulose fibers, ${ }^{9}$ these aerogels are opaque and show relatively high bulk densities. Improving mechanical properties of aerogels with retaining their characteristic properties such as transparency and high porosity is a challenging task.

Organic-inorganic hybrid networks obtained from organotrialkoxysilanes are promising for realizing aerogels with improved strength and flexibility. It has been reported that polymethylsilsesquioxane ( $\mathrm{PMSQ}, \mathrm{CH}_{3} \mathrm{SiO}_{3 / 2}$ ) aerogels, which are obtained solely from methyltrimethoxysilane (MTMS) as the precursor, display high strength and flexibility against both compression and bending deformation. ${ }^{10}$ However, the appearance of the aerogels is opaque, due to the coarsened pore structure. Generally, preparing monolithic gels only from such organotrialkoxysilanes requires innovative designs of the synthetic conditions, due to hydrophobicity and steric hindrance of organic groups. ${ }^{11}$ Macroscopic phase separation between hydrophobic condensates and polar aqueous solvents can easily occur before the gelation takes place. Even in PMSQ, which is the most simple polyorganosilsesquioxane, the synthetic conditions in which monolithic gels can be obtained are severely limited. ${ }^{12}$ In most cases, since insufficient suppression of phase separation tendency leads to pore structure in submicron or even larger scales, only opaque PMSQ gels are obtained. Obtaining transparent aerogels requires a precise control of the condensates and skeletal network in a nanometer scale with high homogeneity for suppressing both the $\mathrm{Mie}^{13}$ and Rayleigh scattering. ${ }^{14}$ Transparent PMSQ aerogels have been for the first time synthesized in 2007, with the aid of a two-step acid-base sol-gel reaction and an appropriate surfactant that stabilizes interfaces between the hydrophobic colloids and aqueous solvent. ${ }^{15}$ In addition to high visible-light transparency, strength, flexibility and resilience against uniaxial compression of the obtained PMSQ aerogels are higher than silica 
aerogels. ${ }^{15,16}$ This resilience against compression can induce so-called "spring-back" during evaporative drying at ambient pressure, ${ }^{17}$ resulting in PMSQ xerogels with comparable transparency and porosity to the corresponding aerogels. The introduced methyl groups and decreased crosslinking density of siloxane bonds are considered to contribute this resilient behavior against compression. However, these transparent PMSQ aerogels still cannot overcome a fracture caused by bending deformations. Such PMSQ random network is composed only of siloxane bonds. An introduction of organic linkers instead of siloxane bonds will increase a separation between $\mathrm{Si}$ atoms and further decrease crosslinking density, which may improve strength against bending deformations. Aerogels having phenylene and hexylene bridges from 1,4-bis(trialkoxysilyl)benzene and 1,6-bis(trialkoxysilyl)hexane thus display reduced friability and/or improved toughness, as reported by Loy et al. and us..$^{18,19}$

The objective of this study is to synthesize and investigate the properties of aerogels based on polymethylsiloxane networks with an ethylene-linking part synthesized from 1,2bis(methyldiethoxysilyl)ethane (BMDEE). To the best of our knowledge, only one study on the aerogels from such bis(methyldialkoxysilyl) monomers, which must be distinguished from bis(trialkoxysilyl) monomers for bridged polysilsesquioxanes, has been reported so far. ${ }^{20}$ Some important differences from bridged polysilsesquioxane materials, such as hydrophobicity originated from the pendant methyl groups, have been revealed in that report. The methyl groups in BMDEE in the present study will also provide distinct hydrophobicity to the resultant aerogels, i.e. there is no need for hydrophobization by a post-synthesis treatment, which is indispensable in hydrophilic networks in the bridged polysilsesquioxane systems. In addition, this precursor forms an ethylene-bridged polymethylsiloxane (EBPMS) network, which is analogous to the PMSQ network except that one-third of the siloxane oxygens is substituted with 
the bridging ethylene group. The resulting EBPMS aerogels reflect the effect of substituted ethylene groups on their macroscopic properties, including improved bendability.

In order to obtain transparent aerogels, we employed and optimized a two-step acid-base solgel reaction in a liquid surfactant-based solution, so as to suppress phase separation between hydrophobic EBPMS condensates and polar solvents. This synthetic tactics was employed in the previous report on aerogels prepared solely from the precursors ethyltrimethoxysilane or vinyltrimethoxysilane, which reports successful syntheses of the aerogels with visible-light transparency. ${ }^{21}$ The similar synthetic procedure has produced transparent wet gels in the present work as well, which then can be processed into transparent and low-density aerogels via supercritical drying. In addition, in order to investigate similarity and difference between EBPMS and PMSQ aerogels, comparisons of mechanical properties of both aerogels have been made, revealing that the EBPMS aerogels show higher bending strength and strain at break, as well as high compressive strength and flexibility. Moreover, the combination of high compressive strength and flexibility allows ambient pressure drying to obtain transparent and low-density xerogels.

\section{EXPERIMENTAL SECTION}

Materials: 1,2-Bis(methyldiethoxysilyl)ethane (BMDEE) was purchased from Gelest Inc. (USA). Methyltrimethoxysilane (MTMS) was purchased from Shin-Etsu Chemical Co. (Japan). Aqueous nitric acid (60\%), acetic acid (99.7\%), methanol, 2-propanol and $n$-hexane were purchased from Kishida Chemical Co., Ltd. (Japan). Distilled water and urea were purchased from Hayashi Pure Chemical Ind., Ltd. (Japan). Surfactant Nonion EH-208 (polyoxyethylene 2ethylhexyl ether) was kindly supplied from NOF Corporation (Japan). Aqueous 
tetramethylammonium hydroxide (TMAOH) (ca. $25 \%$ ) and $n$-hexadecyltrimethylammonium bromide (CTAB) were purchased from Tokyo Chemical Industry Co., Ltd. (Japan). All chemicals were used without further purification.

Preparation of EBPMS aerogels and xerogels: An aerogel EBPMS-80G was synthesized as follows: First, BMDEE $(1.0 \mathrm{~mL})$ and $5 \mathrm{mM}$ nitric acid $(1.0 \mathrm{~mL})$ were mixed in a sealed glass vial and vigorously stirred for $30 \mathrm{~min}$ in order to sufficiently promote the hydrolysis of ethoxy groups. Surfactant EH-208 $(0.60 \mathrm{~mL})$ was then added into the mixture under stirring and the reaction vial was transferred into an ice bath, in order to suppress the reaction rate of subsequent polycondensation under a basic condition. After $3 \mathrm{~min}, 1.5 \mathrm{M}$ TMAOH $(0.40 \mathrm{~mL})$ was added to the reaction solution and stirred for $1 \mathrm{~min}$. The reaction solution was subsequently transferred to a polystyrene container and rested in an oven at $80{ }^{\circ} \mathrm{C}$, followed by gelation and aging for $4 \mathrm{~d}$. The obtained gel was then taken out from the container and soaked in water for further aging at $60{ }^{\circ} \mathrm{C}$ for $1 \mathrm{~d}$, and then washed by immersing in fresh methanol and 2-propanol at $60{ }^{\circ} \mathrm{C}$, each for three times with a duration of at least $8 \mathrm{~h}$. The obtained alcogel containing 2-propanol as a pore liquid was supercritically dried in an autoclave by keeping $80{ }^{\circ} \mathrm{C}$ and $14 \mathrm{MPa}$ for $10 \mathrm{~h}$ under $20 \mathrm{~mL} \mathrm{~min}^{-1}$ of $\mathrm{CO}_{2}$ flow. A dried gel obtained from this process is denoted by an aerogel. A dried gel obtained with the following drying process is denoted by a xerogel: After washing with 2-propanol, further solvent exchange with $n$-hexane was performed on the gel. The gel was immersed in fresh $n$-hexane at $40{ }^{\circ} \mathrm{C}$ for three times with a duration of at least $8 \mathrm{~h}$, followed by evaporative drying at ambient pressure and room temperature. Complete drying required 2-3 d.

Preparation of PMSQ aerogels: Synthetic procedure of PMSQ aerogels was designed by referring to the previous report. ${ }^{16}$ An aerogel PMSQ-14 was prepared as follows: Urea $(0.60 \mathrm{~g})$ and CTAB $(0.080 \mathrm{~g})$ were dissolved in $5 \mathrm{mM}$ acetic acid $(2.0 \mathrm{~mL})$ and MTMS $(1.0 \mathrm{~mL})$ was then 
added to the solution under stirring. After $30 \mathrm{~min}$, the reaction solution was transferred to a polystyrene container, followed by gelation and aging for $4 \mathrm{~d}$ in an oven at $60{ }^{\circ} \mathrm{C}$. Subsequent procedures were identical to those of EBPMS systems.

Characterizations: Microstructural morphology was observed by using a field emission scanning electron microscope (FE-SEM), JSM-6700F (JEOL Ltd., Japan). Observed samples were coated in advance with Pt by using an ion sputtering device JFC-1600 (JEOL Ltd., Japan). Visible light transmittance was measured by a V-670 UV-Vis-NIR spectrophotometer (JASCO, Japan) equipped with an integrating sphere. Obtained transmittance data at the wavelength of $550 \mathrm{~nm}$, with estimated errors of $1.5-2 \%$, were normalized into those corresponding to $10 \mathrm{~mm}$ thick samples using the Lambert-Beer equation. A whole spectrum (from $380 \mathrm{~nm}$ to $780 \mathrm{~nm}$ ) of a typical sample is shown in Figure S1. Linear shrinkage was calculated from the lengths of a sample mold and resultant aerogels measured with a digital caliper with estimated errors of 3$6 \%$. Mechanical tests were carried out with a material tester, EZ Graph (Shimadzu Corporation, Japan). In uniaxial compression-decompression tests, samples were compressed until strain reached $50 \%$ and then decompressed. Crosshead speed was $0.50 \mathrm{~mm} \min ^{-1}$ both on compressing and decompressing processes. In the case of three point bending tests, aerogels in size of ca. $10 \times 30 \times 4 \mathrm{~mm}^{3}$ were used for measurement. The span between two supports was 20 $\mathrm{mm}$. Crosshead speed was $0.25 \mathrm{~mm} \mathrm{~min}^{-1}$. The molecular-level structure of obtained aerogels was investigated by ${ }^{29} \mathrm{Si}$ solid-state cross-polarization magic angle spinning (CP/MAS) NMR using an NMR spectrometer Avance III 800US Plus (Bruker Corporation, Germany) under a static magnetic field of $18.8 \mathrm{~T}$. The contact time for cross polarization was fixed at $5.5 \mathrm{~ms}$ and the spinning rate of samples was kept at $15 \mathrm{kHz}$. The ${ }^{29} \mathrm{Si}$ chemical shifts were expressed as values relative to tetramethylsilane by referring to the signal at $-9.66 \mathrm{ppm}$ for 
hexamethylcyclotrisiloxane as an external reference. Nitrogen adsorption-desorption measurements at $77 \mathrm{~K}$ were carried out by using BELSORP-max (MicrotracBEL Corp., Japan). Before the measurements, samples (typically ca. $0.020 \mathrm{~g}$ ) were degassed in a sample cell under vacuum at $80{ }^{\circ} \mathrm{C}$ for $24 \mathrm{~h}$. Obtained adsorption isotherms were used to calculate the BrunauerEmmett-Teller (BET) specific surface areas and the Barrett-Joyner-Halenda (BJH) pore size distributions.

\section{RESULTS AND DISCUSSION}

Chemical reactions involved in the present work are described in Scheme 1. First, we investigated the effects of starting compositions, especially the concentration of base catalyst and volume fraction of surfactant on the properties of aerogels. Among various synthetic parameters, these two are similarly important as in the PMSQ system, where the $\mathrm{pH}$ at gelation and the amount of surfactant have a critical role in forming transparent gels. ${ }^{22}$ Then, an optimization of the process for obtaining transparent and low-density xerogels has been conducted. Comparisons of mechanical properties to those of PMSQ aerogels with similar bulk densities were also made.

\section{Effect of the concentration of base catalyst}

Transparency and linear shrinkage of obtained EBPMS aerogels are found to be dependent on the concentration of base catalyst used. Figure 1 shows the dependence of light transmittance and linear shrinkage of aerogels on the concentration of TMAOH solution gelled at 40, 60 and $80{ }^{\circ} \mathrm{C}$. As shown in Figure 1a, while light transmittance increases with the increasing concentration of $\mathrm{TMAOH}$ in the lower concentration region, aerogels obtained by using relatively high concentration show almost constant light transmittance, except the aerogel 
prepared using $1.5 \mathrm{M} \mathrm{TMAOH}$ at $80{ }^{\circ} \mathrm{C}$. Similarly to the previously reported polyorganosilsesquioxane systems, ${ }^{21,22}$ the pore structure of the resultant EBPMS gels becomes finer under higher $\mathrm{pH}$, resulting in the more transparent aerogels. The drop of transmittance at $1.5 \mathrm{M}$ and $80{ }^{\circ} \mathrm{C}$ is presumably caused by coarsening through dissolution-reprecipitation of the pore skeletons. Under such strong basic conditions, the formed siloxane bonds may undergo hydrolysis/alcoholysis followed by reprecipitation, resulting in a more coarsened pore structure. Inhomogeneous transparency of the aerogel (Figure S2) supports the possibility of partial dissolution of the network. Subsequently, relationships between linear shrinkage, the concentration of $\mathrm{TMAOH}$ and gelation temperature were investigated. Large shrinkage of the gels after supercritical drying was observed in the gels prepared at $40{ }^{\circ} \mathrm{C}$, and it reduces the transparency of wet gels, as compared to the gels prepared at $80{ }^{\circ} \mathrm{C}$. This large shrinkage during supercritical drying is attributed to stresses from differences in thermal expansion coefficients of the solid and liquid phases and syneresis when forming additional siloxane bonds. ${ }^{23}$ Obviously, the linear shrinkage increases in the overall concentration region as the gelation temperature decreases as shown in Figure 1b. This large shrinkage highly densifies the resultant aerogels (e.g. volume shrinkage of the aerogel gelled at $40{ }^{\circ} \mathrm{C}$ with $0.60 \mathrm{M} \mathrm{TMAOH}$ is 2.9 times higher than that of at $80{ }^{\circ} \mathrm{C}$, assuming isotropic shrinkage), leading to less transparency. At the gelation temperature of $40{ }^{\circ} \mathrm{C}$ and $60^{\circ} \mathrm{C}$, linear shrinkage of the resultant aerogels first increases and then decreases with an increasing concentration of TMAOH. However, the linear shrinkage of the gel prepared at $80{ }^{\circ} \mathrm{C}$ monotonically increases with the TMAOH concentration. These results suggest that, at gelation temperatures of 40 and $60{ }^{\circ} \mathrm{C}$, the increasing TMAOH concentration can promote the strengthening of gel skeletons, while the siloxane bonds tend to undergo hydrolysis/alcoholysis as the TMAOH concentration increases at $80{ }^{\circ} \mathrm{C}$, resulting in the larger 
shrinkage. This consideration is consistent with the above-mentioned transmittance drop caused by the partial dissolution of the gel. Notice that we also checked the reproducibility; values such as light transmittance and linear shrinkage of duplicated samples are within the range of the estimated errors described in Experimental, even for the sample with an inhomogeneous appearance shown in Figure S2. In addition, the reproducibility and errors are comparable to the previously reported polymethylsilsesquioxane ${ }^{24}$ and polyvinylsilsesquioxane ${ }^{21}$ aerogels, the latter of which were prepared in a closely similar synthetic procedure. From these results shown in Figure 1, it is indicated that gelation at $80{ }^{\circ} \mathrm{C}$ and a moderate concentration of TMAOH (ca. 0.40-0.60 M) are appropriate to obtain transparent and low-density EBPMS aerogels.

\section{Effect of the volume fraction of surfactant}

The volume fraction of liquid surfactant EH-208, which acts both as a solvent and as a suppressor of phase separation, also affects the linear shrinkage and visible-light transparency of the resultant aerogels. Figure 2 shows the dependence of light transmittance and linear shrinkage of the resultant aerogels on the volume fraction of EH-208. As observed in Figure 2a, the tendencies of light transmittance are almost similar in both $60{ }^{\circ} \mathrm{C}$ and $80{ }^{\circ} \mathrm{C}$ gelation systems, although the transmittance of aerogels gelled at $60{ }^{\circ} \mathrm{C}$ is slightly lower than those at $80{ }^{\circ} \mathrm{C}$ in the high volume fraction region. Light transmittance values between the volume fractions of 0.12 0.25 reach as high as ca. $80 \%$ in both $60{ }^{\circ} \mathrm{C}$ and $80{ }^{\circ} \mathrm{C}$ gelation systems. When the volume fraction of EH-208 is lower than 0.12 , the phase separation induced by polycondensation cannot be suppressed sufficiently, ${ }^{22}$ resulting in lower transparency. Conversely, light transmittance decreases when the volume fraction is higher than 0.25 , presumably because the concentration of precursor is too low to form fine and homogeneous network and porous structures. Figure $2 \mathrm{~b}$ shows the dependence of linear shrinkage on the volume fraction of $\mathrm{EH}-208$ at $60{ }^{\circ} \mathrm{C}$ and $80{ }^{\circ} \mathrm{C}$ 
gelation. While the linear shrinkage in $80{ }^{\circ} \mathrm{C}$ gelation system is relatively constant and is at most ca. $10 \%$, the linear shrinkage in $60{ }^{\circ} \mathrm{C}$ largely increases to ca. $20 \%$ with the increasing volume fraction of EH-208. This increased shrinkage contributes to the decrease of light transmittance in the higher volume fraction region as mentioned above. These results suggest that an appropriate volume fraction of EH-208 is necessary to achieve high light transparency of resultant aerogels.

\section{Preparation of transparent xerogels by ambient pressure drying}

Based on the above results, we designed the optimal synthetic conditions for obtaining transparent and low-density xerogels. The optimized starting composition and synthetic conditions are listed in Table 1. Samples are denoted as "EBPMS- $Y G(x)$ ", where $Y$ means the gelation temperature and $\mathrm{x}$ is attached when a gel is dried by evaporative drying to obtain a xerogel. Figure $3 \mathrm{a}$ and $3 \mathrm{~b}$ shows the appearance of aerogels and xerogels prepared at $60{ }^{\circ} \mathrm{C}$ (EBPMS-60G, EBPMS-60Gx) and $80{ }^{\circ} \mathrm{C}$ (EBPMS-80G, EBPMS-80Gx). It can be clearly observed that EBPMS-80Gx displays almost no shrinkage, while EBPMS-60Gx shows large shrinkage after evaporative drying. Actually, light transmittance and bulk density show similar values in the EBPMS-80G aerogel and xerogel, while bulk density of EBPMS-60Gx is higher than EBPMS-60G by a factor of 2.7 (See Table 1). This difference is related with their compressive deformation behaviors. Figure S3 shows stress-strain curves obtained from uniaxial compression tests on EBPMS-60G and EBPMS-80G aerogels. These curves elucidate the high resilience after the decompression of EBPMS-80G, which enables recovery from shrinkage exerted during evaporative drying, resulting in the low-density, transparent xerogel (EBPMS80Gx). Nitrogen adsorption-desorption isotherms and the BJH pore size distributions of EBPMS-80G and EBPMS-80Gx are shown in Figure S4. It would be a controversial approach 
to apply the gas adsorption measurement on highly porous aerogels in order to evaluate mesopore size distributions, due to the shrinkage induced by the capillary condensation of nitrogen in mesopores. ${ }^{25}$ However, the almost perfect match of isotherms qualitatively suggests that both the aerogel and xerogel are composed of similar mesopore structures. Microscopic analysis using FE-SEM also supports this interpretation. As shown in Figure S5, there is no apparent change in the morphologies of EBPMS-80G and EBPMS-80Gx.

The above-mentioned higher resilience of EBPMS-80G as compared to that of EBPMS-60G is derived from the strengthened network due to the enhanced polycondensation reaction of silanols during aging at the higher temperature. Similarly to the previously reported hierarchically porous PMSQ system, ${ }^{26}$ aging under strong base conditions promotes the additional siloxane formation and the dissolution-reprecipitation reactions on gel skeletons. At higher temperature, these reactions take place more intensively, and thus, the resultant gel skeletons become more elastic. A decrease in the BET specific surface area from $797 \mathrm{~m}^{2} \mathrm{~g}^{-1}$ to $599 \mathrm{~m}^{2} \mathrm{~g}^{-1}$ indicates the intensive rearrangement on the pore skeletons. The ${ }^{29} \mathrm{Si}$ NMR spectra shown in Figure $3 \mathrm{c}$ reveal that the amount of $\mathrm{D}^{1}$ species $\left(-13 \mathrm{ppm}, \mathrm{CH}_{3} \mathrm{Si}(\mathrm{OSi})\left(\mathrm{OC}_{2} \mathrm{H}_{5} / \mathrm{H}\right)\right)$ in EBPMS-80G is smaller than that of EBPMS-60G. This result supports the enhanced polycondensation in the network during aging. Two shoulders (-10 and $-17 \mathrm{ppm})$ of $\mathrm{D}^{1}$ and $\mathrm{D}^{2}(-21 \mathrm{ppm})$ peaks are presumably attributed to Si nuclei in small cyclic structures. According to the literature, ${ }^{27}$ it has been confirmed in crosslinked polydimethylsiloxane systems that Si nuclei constituting small siloxane rings show a resonance peak slightly shifted toward the lower magnetic field, compared to those of $\mathrm{Si}$ in extended siloxane polymers. The precursor BMDEE is inclined to form condensates insoluble in water under dilute acid conditions (See Figure S6 and Table S1.), which should be composed of siloxane rings with kinetically- or thermodynamically-stabilized numbers of 
members. A part of these cyclic structures should be incorporated into the resultant molecular network during the following polycondensation in basic conditions. These cyclization phenomena are frequently reported in acid-catalyzed alkylene-bridged alkoxysilane systems. ${ }^{20,28}$

\section{Comparison of mechanical properties to PMSQ aerogels}

In order to consider the effect of introduced ethylene bridges, a comparison of mechanical properties to PMSQ aerogels with similar bulk densities has been performed. Synthetic conditions and properties of EBPMS and PMSQ aerogels discussed here are listed in Table 2. Two EBPMS (EBPMS-15 and EBPMS-20, the number represents bulk density) and PMSQ (PMSQ-14 and PMSQ-20) aerogels were subjected for comparison. These two EBPMS aerogels were prepared in an identical procedure except gelation temperature, resulting in different bulk densities due to the shrinkage during supercritical drying (ca. $10 \%$ linear shrinkage for EBPMS20, while no obvious shrinkage observed for EBPMS-15). Since bulk densities of these EBPMS aerogels are similar to those of PMSQ aerogels, the differences in mechanical properties can be regarded as reflecting differences in molecular-level structures.

Mechanical properties were investigated via uniaxial compression up to $50 \%$ strain and three point bending tests. Figure 4 shows stress-strain curves obtained from uniaxial compressiondecompression and three point bending tests on the EBPMS and PMSQ aerogels. In compression, the EBPMS-15 aerogels exhibit similar compressive stress at $50 \%$ compression and lower resilience after unloaded as compared to PMSQ-14, but values of both compressive stress and resilience are lower in EBPMS-20 as compared to PMSQ-20 (Figure 4a and 4b). In particular, EBPMS-20 shows even lower resilience than EBPMS-15, probably because of less crosslinked networks with a higher amount of remaining silanol resulted from the lower gelation temperature. In the case of PMSQ, it has been revealed that most of the silicon atoms are 
connected each other with three siloxane bonds, ${ }^{29}$ and this stiffness should contribute to the elastic deformation behaviors.

On the other hand, EBPMS aerogels exhibit superior deformation behaviors with respect to three point bending (Figure 4c and 4d). As shown in Figure 4c, EBPMS-15 shows much higher bending strength compared to PMSQ-14, while the bending strains at break are similar in both systems. In the case of EBPMS-20, although the slopes of stress-strain curves are similar to PMSQ-20, higher bending strains at break are obtained (see also Figure 5 for a photograph). The improved tolerance against bending especially in EBPMS-20 should reflect the effect of introduced organic bridges. Note that the slope of curves decreases with increasing bending strain is observed both on EBPMS-15 and EBPMS-20. These behaviors are derived from the relaxation of stress, which is clarified in the intermittent bending tests shown in Figure 6. While the crosshead stops for $300 \mathrm{~s}$ at each point with keeping constant strains, EBPMS-20 shows a larger decrease in bending stress compared to PMSQ-20. Large stress relaxations on deformation such as stretching are well known in various kinds of organic polymers and organicinorganic hybrids. Although several studies reveal that introducing larger organic moieties enhances the viscoelastic behavior in silica-based polysiloxane films ${ }^{30}$ and silicapolydimethylsiloxane hybrids, ${ }^{31}$ reports on such large stress relaxation on finely porous, monolithic polysiloxane materials have strictly been limited. These unusual viscoelastic behaviors in the polysiloxane network with the short organic chains cannot be explained without an introduction of one-dimensional structures in the network. One possibility is that the EBPMS aerogels are partially composed of a ladder-like polysiloxane structure incorporated in the branched network, as reported in the polymers from bis(methyldialkoxysilyl) precursors with organic bridges that can interact with attractive forces, ${ }^{32,33}$ though there is a lack of such 
interactions in the EBPMS network. These results demonstrate that appropriate substitutions of siloxane bonds with organic bridges can realize enhanced flexibility against various deformation modes including bending in polysiloxane-based aerogels, and may also realize a good balance of flexibility and rigidity, derived from organic and inorganic crosslinking parts, respectively.

\section{CONCLUSIONS}

Transparent, monolithic ethylene-bridged polymethylsiloxane aerogels have been successfully obtained for the first time. Light transmittance and linear shrinkage of the aerogels vary with the concentration of base catalyst and the volume fraction of liquid surfactant. In addition, gelation temperature also affects the mechanical properties of the resultant gels. Aerogel samples denoted as EBPMS-60G (gelled at $\left.60{ }^{\circ} \mathrm{C}\right)$ and EBPMS-80G $\left(80{ }^{\circ} \mathrm{C}\right)$ show similar transparency and bulk density; however, EBPMS-80G exhibits higher compressive stress and resilience after unloading in uniaxial compression tests, due to enhanced polycondensation and neck growth by a dissolution-reprecipitation process. This superior recovery against compression enables ambient pressure evaporative drying to obtain xerogels with comparable light transmittance (76\%) and bulk density $\left(0.19 \mathrm{~g} \mathrm{~cm}^{-3}\right)$ to those of the corresponding aerogel. Compared to the previously reported PMSQ aerogels, resilience is lower in EBPMS presumably due to the less rigid network structure, while the EBPMS aerogels exhibit higher bending strength and strain compared to PMSQ. Large stress relaxation is also observed, which is generally seen in organic polymers. These enhanced viscoelastic behaviors in EBPMS should reflect the effect of introduced ethylene-bridging parts. Although further studies are needed, these organic-inorganic hybrid polysiloxane systems would lead to even higher bending flexibility and open a way to the mass production for versatile applications to thermal insulation and others. 

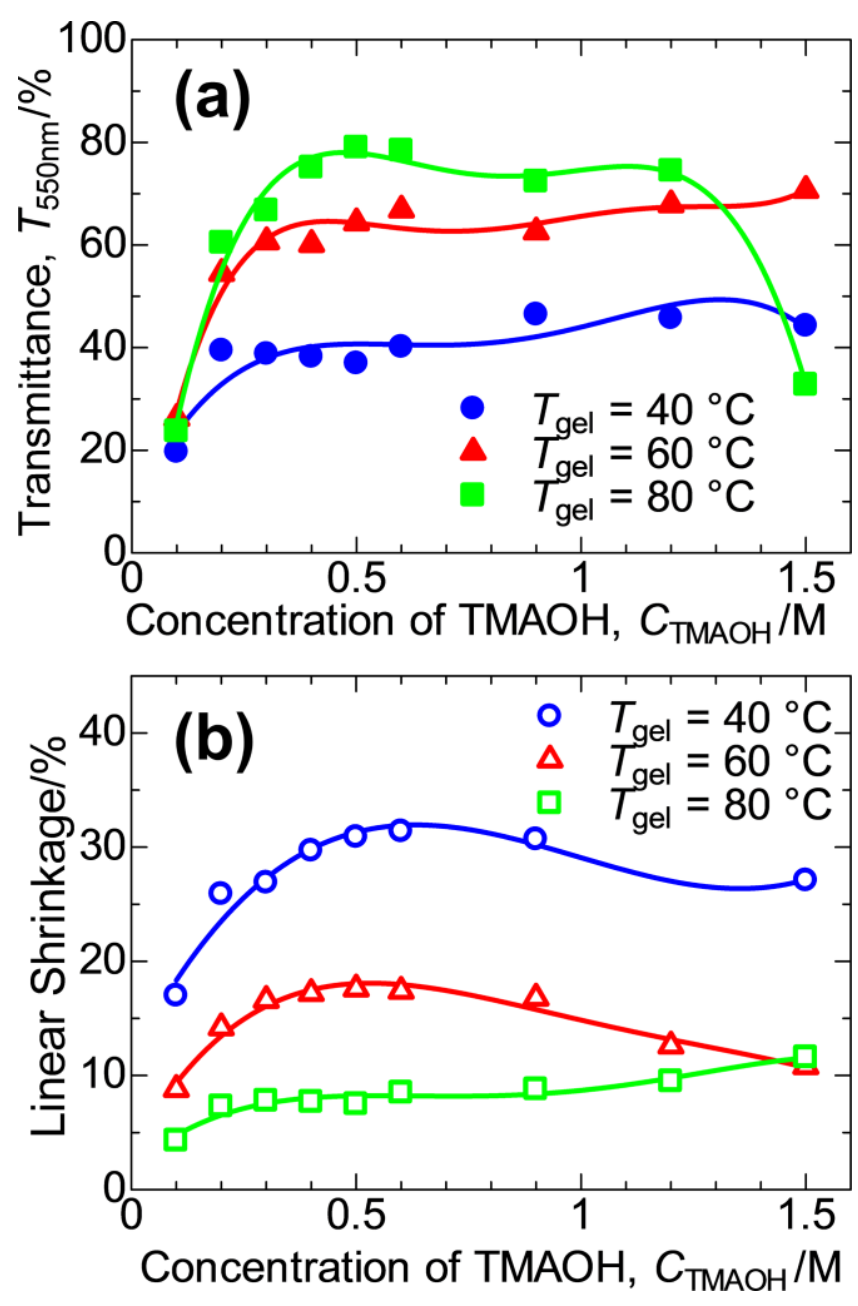

Figure 1. Relationship between the concentration of $\mathrm{TMAOH}$ and (a) light transmittance (corresponding values to those of $10 \mathrm{~mm}$-thick samples) and (b) linear shrinkage of aerogels gelled at 40,60 and $80^{\circ} \mathrm{C}$. Other starting compositions were fixed as follows: BMDEE (1.0 mL), $5 \mathrm{mM}$ nitric acid $(1.0 \mathrm{~mL}), \mathrm{EH}-208(1.0 \mathrm{~mL})$, and TMAOH solution $(1.0 \mathrm{~mL})$. 

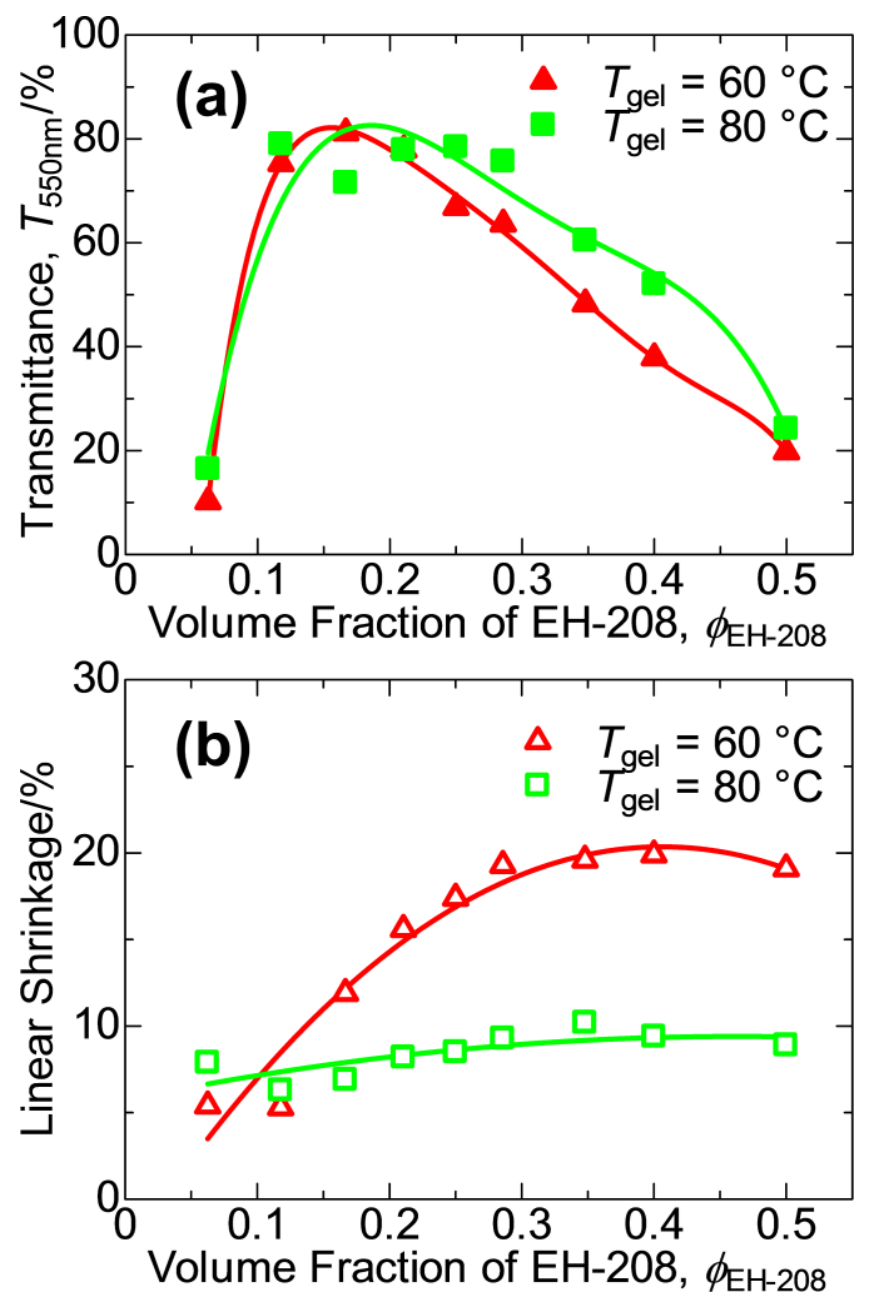

Figure 2. Relationship between the volume fraction of EH-208 and (a) light transmittance and (b) linear shrinkage of aerogels gelled at 60 and $80{ }^{\circ} \mathrm{C}$. The volume fraction of EH-208 was altered by changing the amount of EH-208 in the starting compositions. The amounts of other starting components were fixed as follows: BMDEE $(1.0 \mathrm{~mL}), 5 \mathrm{mM}$ nitric acid $(1.0 \mathrm{~mL})$, and 0.60 M TMAOH (1.0 mL). 

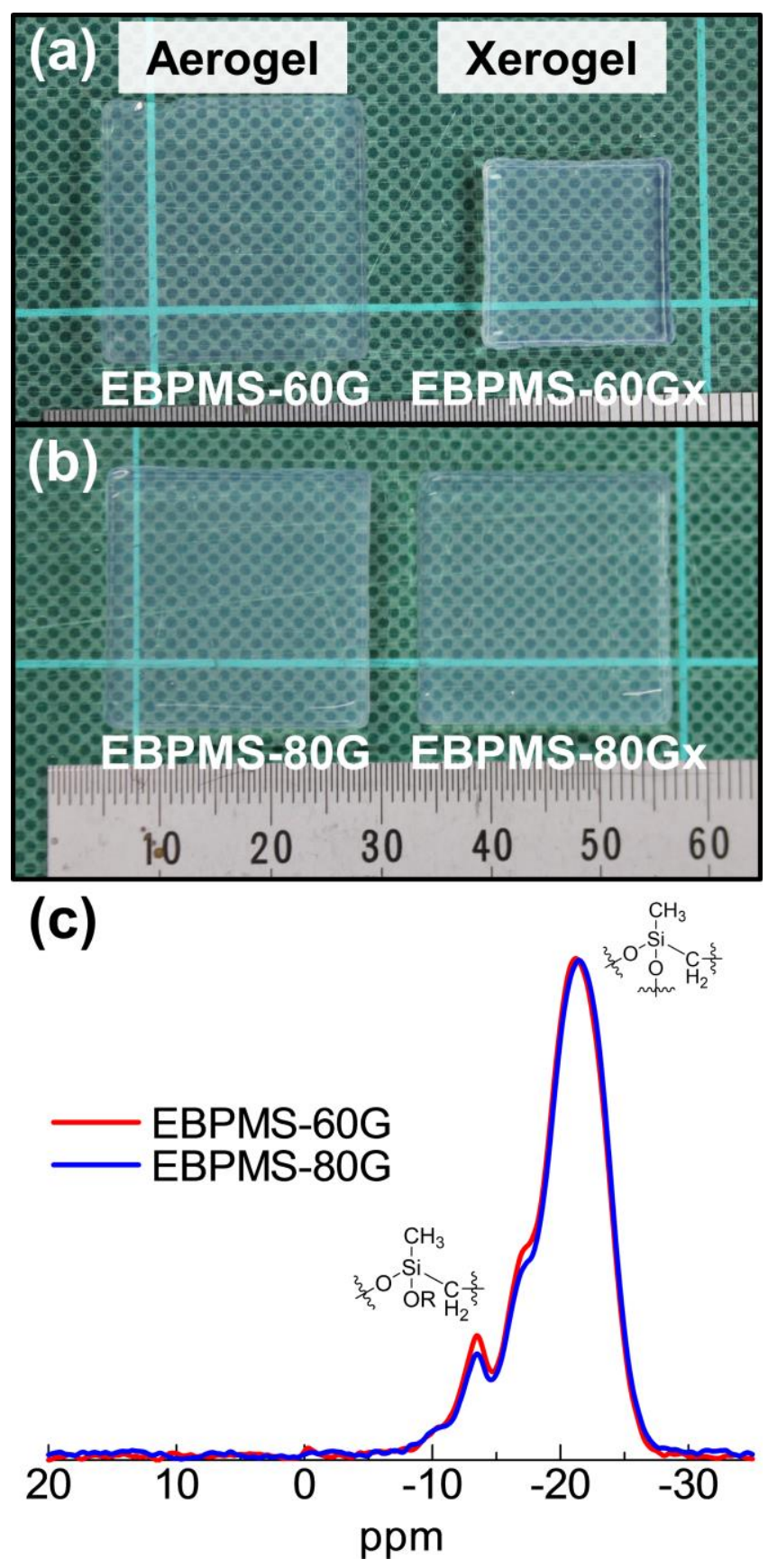

Figure 3. Appearance of transparent EBPMS aerogel and xerogel gelled at (a) 60 and (b) $80{ }^{\circ} \mathrm{C}$.

(c) ${ }^{29} \mathrm{Si}$ solid-state CP/MAS NMR spectra of the aerogel samples gelled at 60 and $80{ }^{\circ} \mathrm{C}$. There is no other peak observed in the range of $155 \mathrm{ppm}$ to $-159 \mathrm{ppm}$. 

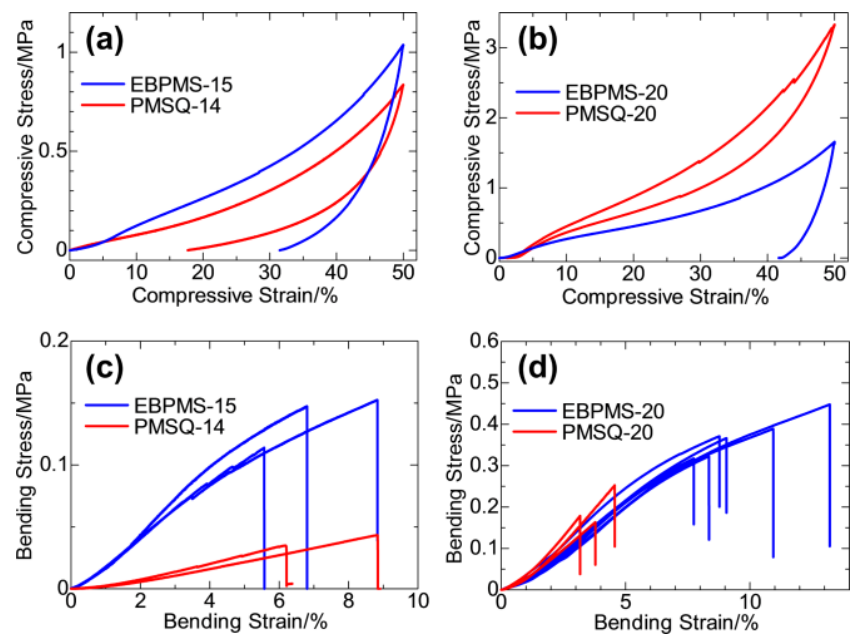

Figure 4. Stress-strain curves obtained from (a), (b) uniaxial compression tests and (c), (d) three point bending tests on EBPMS and PMSQ aerogels.

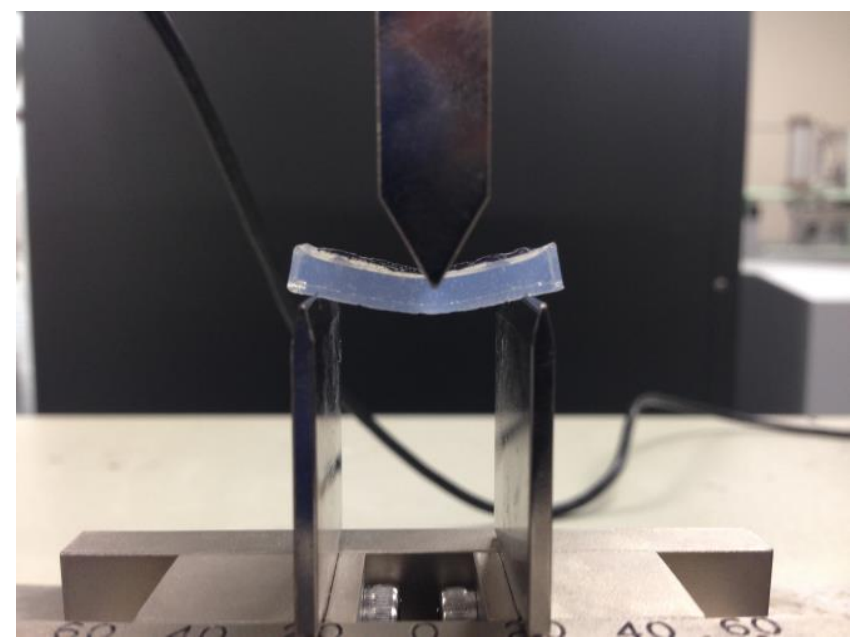

Figure 5. Large bending deformation of a typical EBPMS-20 aerogel. 

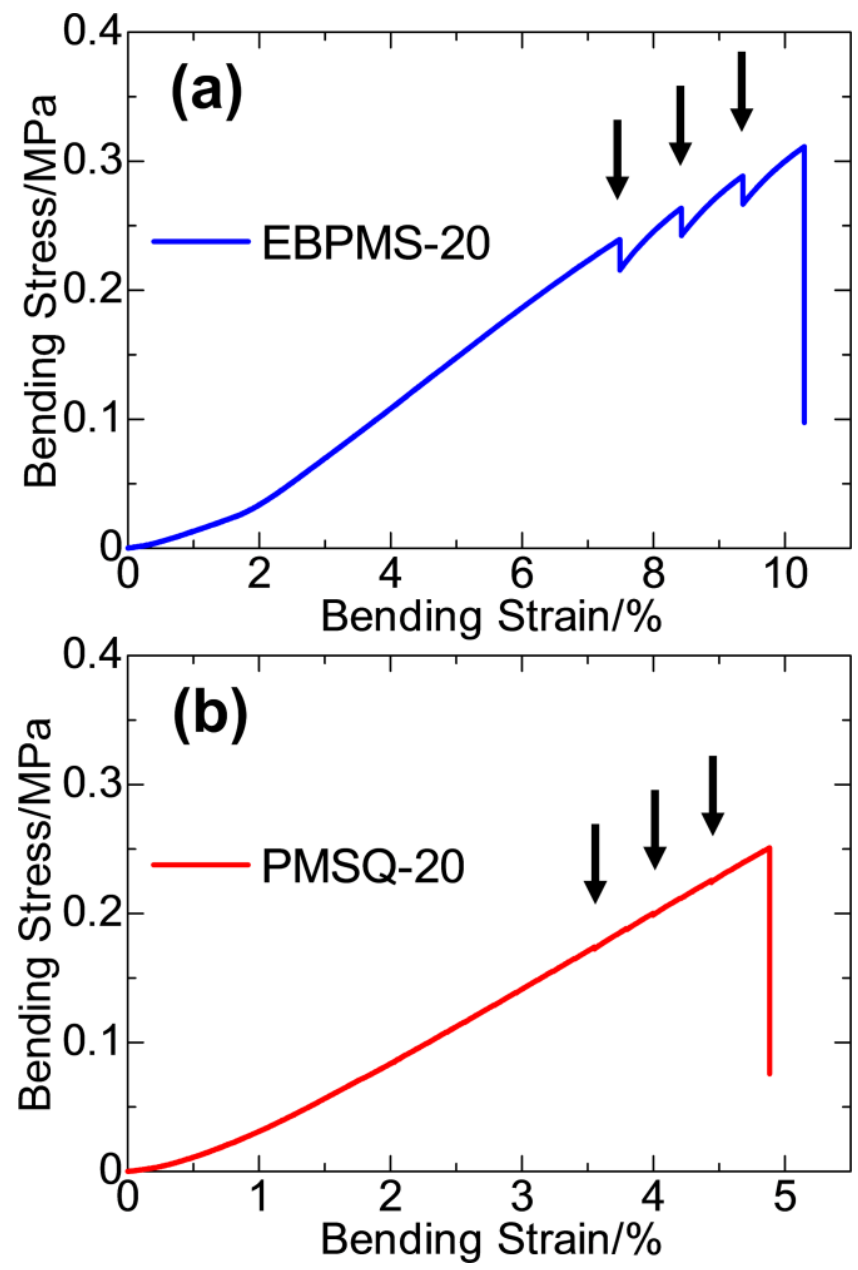

Figure 6. Stress-strain curves obtained from intermittent three point bending tests on (a) EBPMS-20 and (b) PMSQ-20 aerogels. Relaxation of bending stress was measured by stopping the crosshead for $300 \mathrm{~s}$ at the arrowed points.

$$
\mathrm{EH}-208: \mathrm{C}_{8} \mathrm{H}_{17}-{ }^{\circ} \times \mathrm{O}_{\mathrm{n}}^{\mathrm{H}}
$$

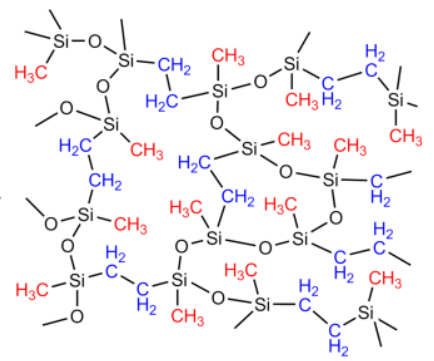

Ethylene-bridged Polymethylsiloxane

\section{EBPMS}

Scheme 1. Strong-acid strong-base 2-step reaction in a liquid surfactant EH-208 employed in the present work. 
Table 1. Synthetic conditions and properties of ethylene-bridged polymethylsiloxane (EBPMS) aerogels and xerogels.

\begin{tabular}{|l|l|l|l|l|}
\hline Sample name & $\begin{array}{l}T_{\text {gel }} \\
/{ }^{\circ} \mathrm{C}\end{array}$ & $\begin{array}{l}T_{550 \mathrm{~nm}^{\mathrm{c}}} \\
/ \%\end{array}$ & $\begin{array}{l}\rho_{\text {bulk }}{ }^{\mathrm{d})} \\
/ \mathrm{g} \mathrm{cm}^{-3}\end{array}$ & $\begin{array}{l}S_{\mathrm{BET}} \\
/ \mathrm{m}^{2} \mathrm{~g}^{-1}\end{array}$ \\
\hline EBPMS-60G & 60 & 83 & 0.19 & 797 \\
\hline EBPMS-80G & 80 & 77 & 0.18 & 599 \\
\hline EBPMS-60Gx & 60 & 69 & 0.51 & 780 \\
\hline EBPMS-80Gx & 80 & 76 & 0.19 & 642 \\
\hline
\end{tabular}

(a) All of the samples listed here were prepared from following amount of starting compositions; 1,2-bis(methyldiethoxysilyl)ethane (BMDEE, $1.0 \mathrm{~mL}$ ), $5 \mathrm{mM}$ nitric acid (1.0 mL), EH-208 (0.60 mL) and 1.5 M tetramethylammonium hydroxide (TMAOH, $0.40 \mathrm{~mL})$. Sample names are denoted in the following form: EBPMS- $Y \mathrm{G}(\mathrm{x})$, where $Y$ is the gelation temperature and $\mathrm{x}$ is attached if the sample has been processed as a xerogel. (b) Gelation (and aging) temperature. (c) Light transmittance at $550 \mathrm{~nm}$, normalized into the value of $10 \mathrm{~mm}$-thick sample, using the Lambert-Beer equation. (d) Bulk density with an estimated error of $5 \%$. (e) Brunauer-Emmett-Teller (BET) specific surface area.

Table 2. Properties of ethylene-bridged polymethylsiloxane (EBPMS) and polymethylsilsesquioxane (PMSQ) aerogels for mechanical comparison studies.

\begin{tabular}{|l|l|l|}
\hline Sample name $^{\mathrm{a})}$ & $\begin{array}{l}\rho_{\text {bulk }} \\
/ \mathrm{g} \mathrm{cm}^{-3}\end{array}$ & $\begin{array}{l}T_{550 \mathrm{~nm}} \\
/ \%\end{array}$ \\
\hline EBPMS-20 & 0.20 & 67 \\
\hline EBPMS-15 & 0.15 & 78 \\
\hline PMSQ-20 & 0.20 & 12 \\
\hline PMSQ-14 & 0.14 & 86 \\
\hline
\end{tabular}

(a) The digit in sample name represents bulk density. Synthetic conditions of the samples listed here were as follows: For EBPMS samples; BMDEE $(1.0 \mathrm{~mL}), 5 \mathrm{mM}$ nitric acid $(1.0 \mathrm{~mL})$, $\mathrm{EH}-208(1.0 \mathrm{~mL}), 0.60 \mathrm{M}$ TMAOH $(1.0 \mathrm{~mL})$, and gelation and aging temperature $\left(60{ }^{\circ} \mathrm{C}\right.$ for EBPMS-20, $80{ }^{\circ} \mathrm{C}$ for EBPMS-15). For PMSQ samples; methyltrimethoxysilane (MTMS, 1.0 
$\mathrm{mL}$ ), $5 \mathrm{mM}$ acetic acid (1.0 mL for PMSQ-20, $2.0 \mathrm{~mL}$ for PMSQ-14), urea (0.60 g), $n$ hexadecyltrimethylammonium bromide $(\mathrm{CTAB}, 0.080 \mathrm{~g})$, and gelation temperature $\left(60^{\circ} \mathrm{C}\right)$.

\section{ASSOCIATED CONTENT}

\section{Supporting Information.}

The Supporting Information is available free of charge via the Internet at http://pubs.acs.org.

Light transmittance spectrum, sample photographs, stress-strain curves, nitrogen adsorptiondesorption isotherms, pore size distributions, FE-SEM images, and data on the generation of insoluble condensates under acidic conditions (PDF)

\section{AUTHOR INFORMATION}

\section{Corresponding Author}

*E-mail: kanamori@kuchem.kyoto-u.ac.jp

\section{ACKNOWLEDGMENT}

The present study has been performed under financial supports from Advanced Low Carbon Technology Research and Development Program (ALCA, JST Japan). The NMR measurements were carried out in the JURC at the Institute for Chemical Research, Kyoto University.

\section{REFERENCES}

(1) Gesser, H. D.; Goswami, P. C. Aerogels and Related Porous Materials. Chem. Rev., 1989, $89,765-788$

(2) Hüsing, N.; Schubert, U. Aerogels-Airy Materials: Chemistry, Structure, and Properties. Angew. Chem. Int. Ed., 1998, 37, 22-45 
(3) Jensen, K. I.; Schultz, J. M.; Kristiansen, F. H. Development of Windows Based on Highly Insulating Aerogel Glazings. J. Non-Cryst. Solids, 2004, 350, 351-357

(4) Baetens, R.; Jelle, B. P.; Gustavsen, A. Aerogel Insulation for Building Applications: A State-of-the-Art Review. Energy Build., 2011, 43, 761-769

(5) Tabata, M.; Adachi, I.; Ishii, Y.; Kawai, H.; Sumiyoshi, T.; Yokogawa, H. Development of Transparent Silica Aerogel over a Wide Range of Densities. Nucl. Instrum. Methods Phys. Res. Sect. A, 2010, 623, 339-341

(6) Tsutsui, T.; Yahiro, M.; Yokogawa, H.; Kawano, K.; Yokoyama, M. Doubling CouplingOut Efficiency in Organic Light-Emitting Devices Using a Thin Silica Aerogel Layer. Adv. Mater., 2001, 13, 1149-1152

(7) Smirnova, I.; Mamic, J.; Arlt, W. Adsorption of Drugs on Silica Aerogels. Langmuir, 2003, $19,8521-8525$

(8) Leventis, N.; Sotiriou-Leventis, C.; Zhang G.; Rawashdeh, A.-M. M. Nanoengineering Strong Silica Aerogels. Nano Lett. 2002, 2, 957-960.

(9) Cai, J.; Liu, S.; Feng, J.; Kimura, S.; Wada, M.; Kuga, S.; Zhang, L. Cellulose-Silica Nanocomposite Aerogels by In Situ Formation of Silica in Cellulose Gel. Angew. Chem. Int. Ed., 2012, 51, 2076-2079

(10) Rao, A. V.; Bhagat, S. D.; Hirashima, H.; Pajonk, G. M. Synthesis of Flexible Silica Aerogels Using Methyltrimethoxysilane (MTMS) Precursor. J. Colloid Interface Sci., 2006, 300, 279-285 
(11) Loy, D. A.; Baugher, B. M.; Baugher, C. R.; Schneider, D. A.; Rahimian, K. Substituent Effects on the Sol-Gel Chemistry of Organotrialkoxysilanes. Chem. Mater., 2000, 12, 3624-3632

(12) Dong, H.; Brook, M. A.; Brennan, J. D. A New Route to Monolithic Methylsilsesquioxanes: Gelation Behavior of Methyltrimethoxysilane and Morphology of Resulting Methylsilsesquioxanes under One-Step and Two-Step Processing. Chem. Mater., 2005, $17,2807-2816$

(13) Alexander, S. Vibrations of Fractals and Scattering of Light from Aerogels. Phys. Rev. B, 1989, 40, 7953-7965

(14) Cao, W.; Hunt, A. J. Improving the Visible Transparency of Silica Aerogels. J. Non-Cryst. Solids, 1994, 176, 18-25

(15) Kanamori, K.; Aizawa, M.; Nakanishi, K.; Hanada, T. New Transparent Methylsilsesquioxane Aerogels and Xerogels with Improved Mechanical Properties. Adv. Mater., 2007, 19, 1589-1593

(16) Kanamori, K.; Nakanishi, K.; Hanada, T. Sol-Gel Synthesis, Porous Structure, and Mechanical Property of Polymethylsilsesquioxane Aerogels. J. Ceram. Soc. Jpn., 2009, 117, $1333-1338$

(17) Prakash, S. S.; Brinker, C. J.; Hurd, A. J.; Rao, S. M. Silica Aerogel Films Prepared at Ambient Pressure by Using Surface Derivatization to Induce Reversible Drying Shrinkage. Nature, 1995, 374, 439-443 
(18) Boday, D. J.; Stover, R. J.; Muriithi, B.; Loy, D. A. Mechanical Properties of Hexyleneand Phenylene-Bridged Polysilsesquioxane Aerogels and Xerogels J. Sol-Gel Sci. Technol., 2012, $61,144-150$

(19) Aoki, Y.; Shimizu, T.; Kanamori, K.; Maeno, A.; Kaji, H.; Nakanishi, K. Low-Density, Transparent Aerogels and Xerogels Based on Hexylene-Bridged Polysilsesquioxane with Bendability. J. Sol-Gel Sci. Technol., DOI: 10.1007/s10971-016-4077-1

(20) Loy, D. A.; Jamison, G. M.; Baugher, B. M.; Myers, S. A.; Assink, R. A.; Shea, K. J. SolGel Synthesis of Hybrid Organic-Inorganic Materials. Hexylene- and Phenylene-Bridged Polysiloxanes. Chem. Mater., 1996, 8, 656-663

(21) Shimizu, T.; Kanamori, K.; Maeno, A.; Kaji, H.; Doherty, C. M.; Falcaro, P.; Nakanishi, K. Transparent, Highly Insulating Polyethyl- and Polyvinylsilsesquioxane Aerogels: Mechanical Improvements by Vulcanization for Ambient Pressure Drying. Chem. Mater., 2016, 28, 68606868

(22) Hayase, G.; Kanamori, K.; Nakanishi, K. Structure and Properties of Polymethylsilsesquioxane Aerogels Synthesized with Surfactant $n$ Hexadecyltrimethylammonium Chloride. Microporous Mesoporous Mater., 2012, 158, 247-252

(23) Scherer, G. W. Stress Development During Supercritical Drying J. Non-Cryst. Solids, 1992, $145,33-40$

(24) Hayase, G.; Kanamori, K.; Maeno, A.; Kaji, H.; Nakanishi, K. Dynamic Spring-back Behavior in Evaporative Drying of Polymethylsilsesquioxane Monolithic Gels for Low-density Transparent Thermal Superinsulators. J. Non-Cryst. Solids, 2016, 434, 115-119 
(25) Reichenauer, G.; Scherer, G. W. Extracting the Pore Size Distribution of Compliant Materials from Nitrogen Adsorption. Colloids Surf., A, 2001, 187-188, 41-50

(26) Zhu, Y.; Morimoto, Y.; Shimizu, T.; Morisato, K.; Takeda, K.; Kanamori, K.; Nakanishi, K. Synthesis of Hierarchically Porous Polymethylsilsesquioxane Monoliths with Controlled Mesopores for HPLC Separation. J. Ceram. Soc. Jpn., 2015, 123, 770-778

(27) Hill, D. J. T.; Preston, C. M. L.; Whittaker, A. K. NMR Study of the Gamma Radiolysis of Poly(dimethyl siloxane) under Vacuum at 303 K. Polymer, 2002, 43, 1051-1059

(28) Loy, D. A.; Carpenter, J. P.; Alam, T. M.; Shaltout, R.; Dorhout, P. K.; Greaves, J.; Small, J. H.; Shea, K. J. Cyclization Phenomena in the Sol-Gel Polymerization of $\alpha, \omega$ Bis(triethoxysilyl)alkanes and Incorporation of the Cyclic Structures into Network Silsesquioxane Polymers. J. Am. Chem. Soc., 1999, 121, 5413-5425

(29) Kanamori, K.; Aizawa, M.; Nakanishi, K.; Hanada, T. Elastic Organic-Inorganic Hybrid Aerogels and Xerogels. J. Sol-Gel Sci. Technol., 2008, 48, 172-181

(30) Atanacio, A. J.; Latella, B. A.; Barbé, C. J.; Swain, M. V. Mechanical Properties and Adhesion Characteristics of Hybrid Sol-Gel Thin Films. Surf. Coat. Technol., 2005, 192, 354364

(31) de la Rosa-Fox, N.; Fernández, J. A. T.; Morales-Flórez, V.; Piñero, M.; Esquivias, L. Creep and Stress Relaxation of Hybrid Organic-Inorganic Aerogels Key Eng. Mater., 2010, 423, $167-172$

(32) Cao, X.; Wang, L.; Li, B.; Zhang, R. Synthesis and Characterization of Ladder-like Phenylene-Bridged Polysiloxanes. Polym. Adv. Technol., 1997, 8, 657-661 
(33) Tang, H.; Sun, J.; Jiang, J.; Zhou, X.; Hu, T.; Xie, P.; Zhang, R. A Novel Aryl AmideBridged Ladderlike Polymethylsiloxane Synthesized by an Amido H-Bonding Self-Assembled Template. J. Am. Chem. Soc., 2002, 124, 10482-10488 
Insert Table of Contents Graphic and Synopsis Here

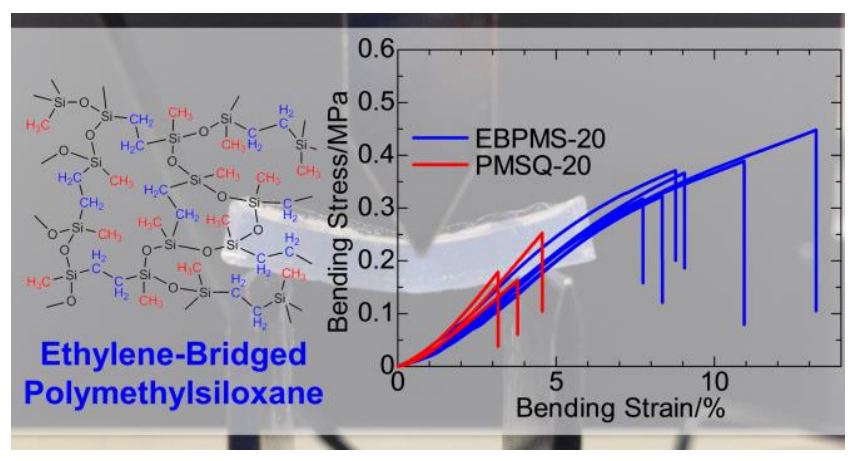




\section{Supporting Information}

\section{TRANSPARENT ETHYLENE-BRIDGED POLYMETHYLSILOXANE AEROGELS AND XEROGELS WITH IMPROVED BENDING FLEXIBILITY}

Taiyo Shimizu ${ }^{\dagger}$, Kazuyoshi Kanamori, ${ }^{*}$, Ayaka Maeno ${ }^{\ddagger}$, Hironori Kaji ${ }^{\ddagger}$ and Kazuki Nakanishi ${ }^{\dagger}$

'Department of Chemistry, Graduate School of Science, Kyoto University, Kitashirakawa, Sakyo-ku, Kyoto 6068502, Japan

Institute for Chemical Research, Kyoto University, Gokasho, Uji-city, Kyoto 611-0011, Japan

\section{Corresponding Author}

*E-mail: kanamori@kuchem.kyoto-u.ac.jp 


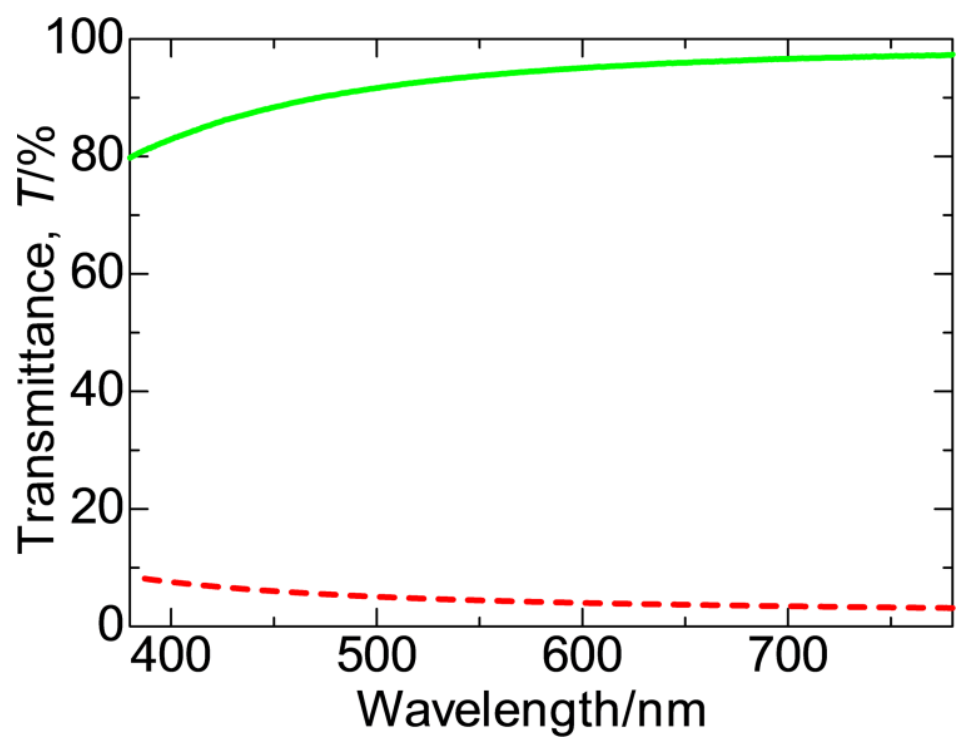

Figure S1. The total light transmittance (solid line) of a typical EBPMS aerogel, ranging from 380 to 780 $\mathrm{nm}$ with broken line representing the diffuse transmittance. The synthetic condition of the measured sample was as follows: BMDEE (1.0 mL), $5 \mathrm{mM}$ nitric acid (1.0 mL), EH-208 (1.0 mL), 0.60 M TMAOH $(1.0 \mathrm{~mL})$, and gelation and aging temperature $\left(80^{\circ} \mathrm{C}\right)$. The thickness of the sample was $2.68 \mathrm{~mm}$.

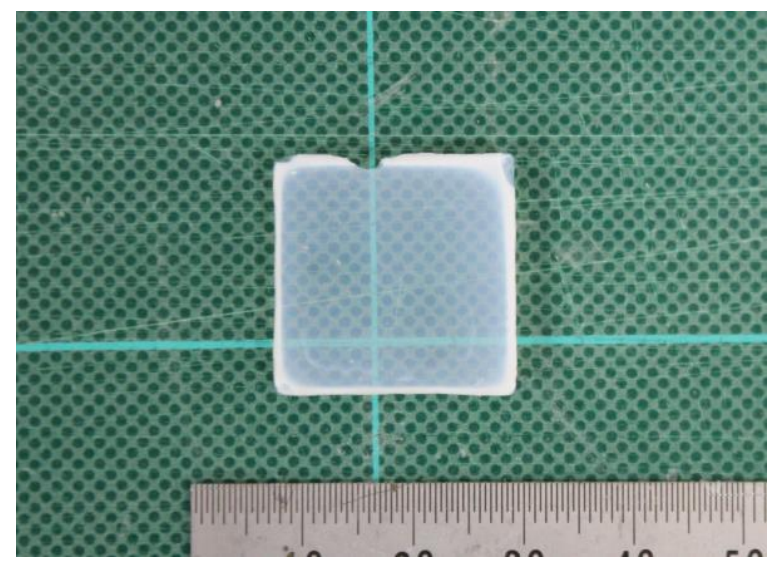

Figure S2. Appearance of an aerogel obtained by using $1.5 \mathrm{M}$ tetramethylammonium hydroxide (TMAOH) and gelled at $80{ }^{\circ} \mathrm{C}$. The circumference became whitish probably due to dissolution-reprecipitation of formed siloxane bonds in the highly basic solution. Starting compositions are as follows; 1,2bis(methyldiethoxysilyl)ethane (BMDEE, $1.0 \mathrm{~mL}), 5 \mathrm{mM}$ nitric acid (1.0 mL), EH-208 (1.0 mL) and 1.5 M TMAOH (1.0 mL). 


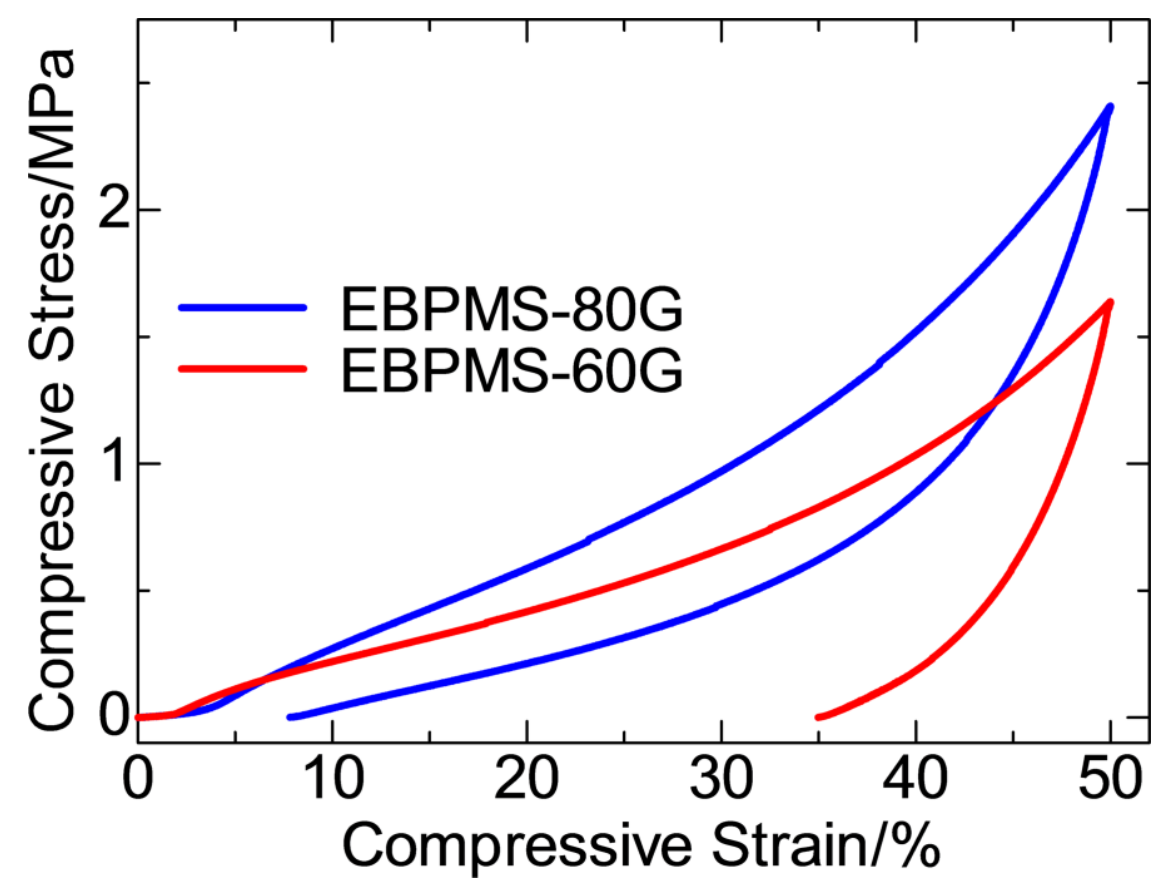

Figure S3. Stress-strain curves obtained from uniaxial compression tests on EBPMS-60G and EBPMS$80 \mathrm{G}$.
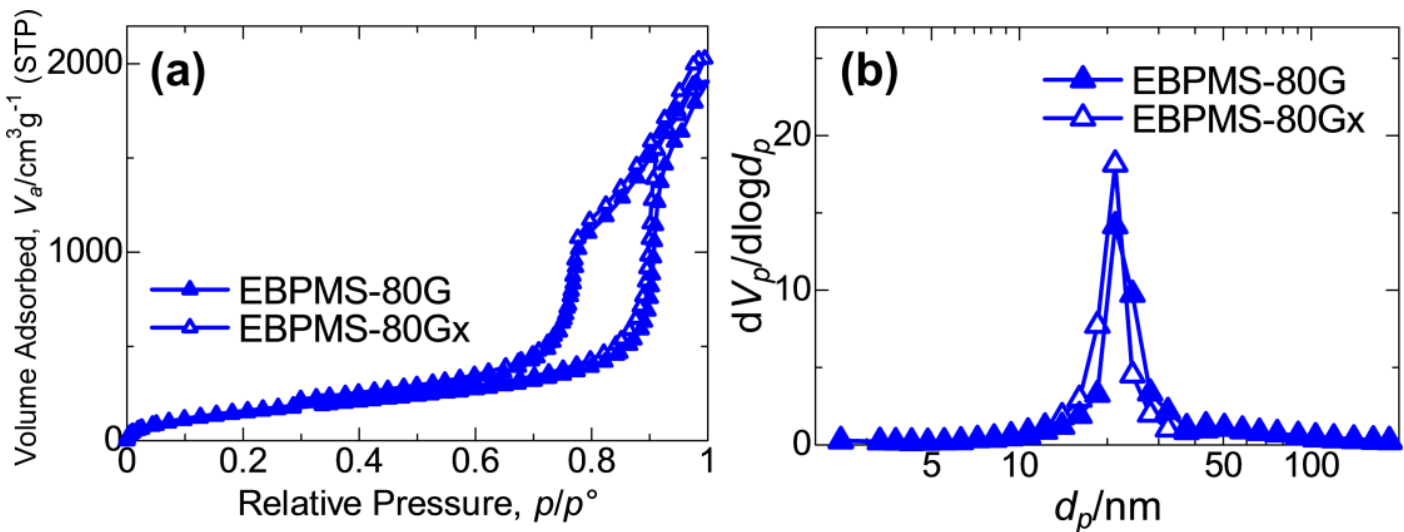

Figure S4. (a) Nitrogen adsorption-desorption isotherms at $77 \mathrm{~K}$ and (b) Barrett-Joyner-Halenda (BJH) pore size distributions of EBPMS-80G and EBPMS-80Gx.

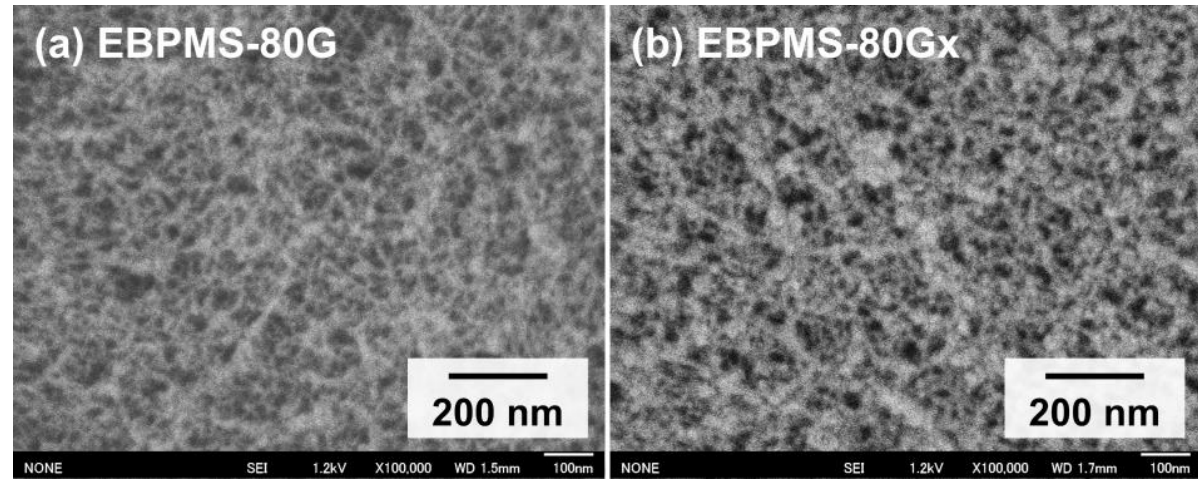

Figure S5. Microstructural morphologies of (a) EBPMS-80G and (b) EBPMS-80Gx. 


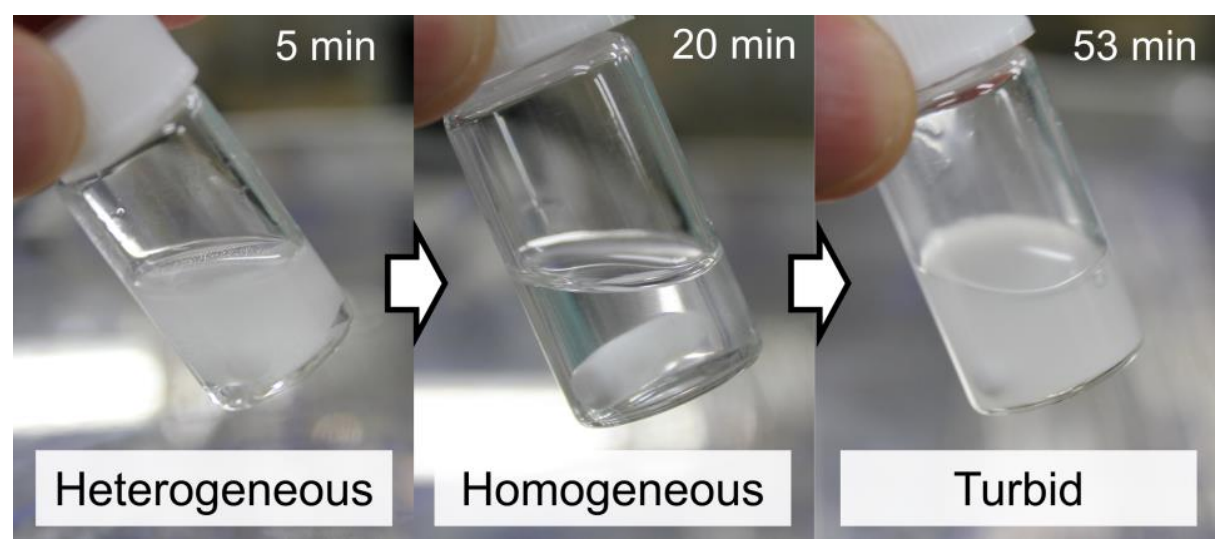

Figure S6. Transition of the appearance of stirred mixture of BMDEE $(1.0 \mathrm{~mL})$ and $5 \mathrm{mM}$ nitric acid (1.0 $\mathrm{mL}$ ). Hydrolysis of ethoxy groups of BMDEE produces ethanol and enables the mixture to become homogeneous, and insoluble compounds generated by condensation of BMDEE derivatives force the solution to get turbid. The times represent duration of stirring.

Table S1. Duration of stirring until the mixture of aqueous nitric acid (1.0 mL) and BMDEE (1.0 mL) become turbid.

\begin{tabular}{|l|l|}
\hline Concentration of aqueous nitric acid & Duration until mixture becomes turbid \\
\hline $5 \mathrm{mM}$ & $53 \mathrm{~min}$ \\
\hline $10 \mathrm{mM}$ & $23 \min 30 \mathrm{~s}$ \\
\hline $50 \mathrm{mM}$ & $7 \min$ \\
\hline $100 \mathrm{mM}$ & $3 \min 10 \mathrm{~s}$ \\
\hline
\end{tabular}

